\title{
Research on the Evolution of Cheongsam Style in the Republican Period and Its Contemporary Application
}

\author{
Yulong Wei \\ School of Art and Design \\ Zhengzhou University of Light Industry \\ Zhengzhou, China
}

\begin{abstract}
Cheongsam is one of the main styles of women's dress in modern China. With the integration of Chinese and Western culture, its style is constantly changing to adapt to modern life. This paper discusses the evolutions of cheongsam style in the republican period, the integration of Chinese and Western types, simplified application and style characteristics after mixing with modern women's dress in different periods. According to the research on the evolutions of its style, the author summed up the developing law of cheongsam style. It helps us further understand and grasp the nature of the world fashion trend and enriches our design techniques. Chinese traditional clothing will show unique fashion charm after innovation and recreation.
\end{abstract}

Keywords—cheongsam; western clothing culture

\section{INTRODUCTION}

Cheongsam is typical national clothing which is harmonious and unified inside and outside. It is regarded as the representative of Chinese clothing culture, and is the most representative traditional clothing of Chinese women. Previously it only refers to the dress of Manchu women, and later with the ethnic fusion, Han women imitated the dress of Manchu women, and modified and improved it. So, it evolved as the main Chinese women's clothing.

After the Xinhai Revolution of 1911, Western clothing concept greatly impacted and enriched traditional Chinese clothing culture, and new styled cheongsam had a greater breakthrough: Chinese women dress style began to develop to the functional and personalized direction. After absorbing the Western women's three-dimensional modeling concept, we had a greater breakthrough in tailoring method and technological details. We began to emphasize the human body curve in cutting. The cheongsam of three-dimensional modeling changing from plane modeling can better reflect the natural beauty of women's body. In today's society, the West still follows three-dimensional modeling method of traditional narrow dress culture system, and only uses the aesthetic features of the Oriental style for reference. However, we blindly cut and change, abandon our national dress and follow the trend of the West. In this way, we lost our own personality and the nature of design - innovation.

This paper tries to sum up the law from changes of cheongsam style in the republican period, and through researching the application of the cheongsam elements of this period in modern clothing, put forward ideas of the use of cheongsam elements in contemporary design. The purpose is to make Chinese clothing design highlight our national characteristics. We can extract the piths of international styles and vigorously promote the development of China's clothing industry.

\section{The CheONGSAM IN THE REPUblicAn PERIOD} DRAWING LESSONS FROM THE FEATURES OF WESTERN DRESS AND GRADUALLY TRANSITING TO MODERN WOMEN'S DRESS

\section{A. In the 1920s, Cheongsam Was Modified and Has Become A Popular Women's Dress}

At the beginning of the 20th Century, the cheongsam was loose, and with straight contour. It still had "large sleeves" with length longer than arm. The lower half of sleeve had colored embroidery with complicated patterns different from the color of sleeve and was folded out to highlight its grand atmosphere. Its collar, lower hem and other parts were finely embroidered. The length of cheongsam approximately extended above the ankle or the middle of the calf, leaving people an impression of solemnity. It is quite different from modern women's simple style.

In the early $1920 \mathrm{~s}$, with the increasingly frequent trade and exchanges between China and Western countries, a large number of western textiles have entered into Chinese market. Meanwhile, the popular concepts of western dress also were brought into China. New aesthetics, such as the slender shape of Paris style, low waist line and miniskirt, began to be reflected on Chinese women's dress in the 1920s. New-style cheongsam became popular. The western ideology and culture and morality began to influence Chinese and Chinese women were no longer wrapped with thick cloth. In this period, newstyle cheongsam had loose waist and was straightly cut. Its length was shortened on or above feet, with small arm hole and loose cuff. The sleeve was shortened to elbow joint or with wrist exposed, entirely presenting in a trumpet shape. The shortened lower hem and sleeves were prominent features of cheongsam in the 1920s, which indicated that women began to show their body beauty moderately. Cheongsam became very popular, and women wore "unlined robe, cotton robe and outerwear" to face the change of season, and matched with other clothes. 
At the end of 1920s, the cheongsam began to shrink waist and cuff. Influenced by European and American popular trend of short skirt, the lower hem was shortened below the knee. The edge was simply rolled with silk yarn. The stand collar also had one or three silk decoration. The style became lighthearted and lively, and the type was obviously changed. The sleeve length of girl students' cheongsam was lower than elbow, and presenting in an inverted trumpet shape. The fulllength reached to the knee. The graceful legs became new visual center. Many modern women love to wear fit cheongsam with western-style sleeve cuff and match with high-heeled shoes and silk stockings. Since then, the western visualized and exposed aesthetics has gradually replaced the eastern introverted and obscure aesthetic consciousness.

\section{B. In the 1930s, Cheongsam Has the Characteristics of A Combination of Chinese and Western Elements}

After entering 1930s, the improved cheongsam has entered a period of great development. At that time, Shanghai was known as "Oriental Paris". It was also the national fashion center. The latest styles of European clothing only became popular every three or four months. In 1930s the European fashion tended to shrunk waist and be feminine. Cheongsam absorbed its features and became tight and fit, and highlighted the curves of breast and hip. The cuff and shoulder became narrow, setting off the graceful figure of Chinese women. The improved cheongsam, which is organically transiting from the traditional style to modern style, is adapted not only to the functional requirements of the modern industrial civilization life, but also to the dressing habit and psychological dependence of the oriental people changing from the traditional agricultural civilization. It becomes the typical clothing of Shanghai-style culture.

In the early 1930s, cheongsam was shortened to the knee. To the middle period, the length of cheongsam was lengthened gradually. In order to facilitate walking, cut two long openings on two sides or even at front and rear, and frap waist to fully show the beautiful curve of women. At the end of 1930s, cheongsam style simply imitated the western style and absorbed its essence of cutting technology and integrated. It used breast dart, shoulder dart, set-in sleeve and shoulder pads. The design details were changing. Even in hot summer high collar was popular. Soft cheongsam was cut with hard collar reaching to ear. The higher the collar was, the more popular the cheongsam was. Later the low collar became popular. The lower the collar was the more fashionable the cheongsam was. Even there was no collar on cheongsam. Sleeve also changed frequently. Sometimes long sleeve was popular and sometimes short sleeve was popular. In a certain period, cheongsam with no sleeve was popular, for it made cheongsam more convenient and fit.

After 1932, the lower hem of cheongsam gradually elongated to ankle or the lower part of calf. Women had to wear high-heeled shoes in order to wear it. It was closely fit to body, so it had to cut opening to facilitate walking. It is an important symbol of cheongsam in the republican period. In 1933, cheongsam was evolved with short opening, no opening and long opening. Designers have modified styles of cheongsam constantly. Especially in some big cities, modern women, communication celebrities and movie stars in Shanghai often wore unconventional and new styles of cheongsam, which greatly promoted its improvement and development.

\section{Summarizes the main characteristics of this period:}

(1)The use of breast dart and waist dart fully reflects the influence of the western dress culture on cheongsam in the republican period. The style was evolved from plane cutting into three-dimensional cutting.

(2) Shoulder seam and set-in sleeve first appeared, which makes the dress more fit.

(3) The cheongsam in the republican period still retains traditional characteristic: symmetrical, rigorous and closedtype contour, reflecting Chinese traditional women's conservative and reserved character.

\section{In the 1940s, Cheongsam Tended to Be Simple and Practical}

In 1940s, cheongsam has become the main clothing of Chinese women, forming a dominating and unified situation. During the war of resistance against Japan, cheongsam tended to be simple for the convenience of activity and due to economic constraints. On the background of wars in the worldwide, the international fashion synchronized with ours, so we all made subtractive design.

Body piece of cheongsam became loose and moderate. The lower hem was shortened to calf. It simplified many gorgeous decorative details. But local details had more changes. It might be high collar, low collar, western-type lapel, flat collar, square collar, round collar, v-shaped collar or even detachable collar lining. There were wide and narrow sleeves. The narrow sleeves may bind arms and may be long to hands. Even there was no sleeve. Even it could be made into vest type or suspender type. The lower hem could be rectangular, round or decorated with flashing.

In 1940s, cheongsam was no longer in the traditional conservative style, and also different from extremely exaggerative style of the West. After modification and improvement, cheongsam has integrated western cutting technology and modern aesthetics. On one hand, cheongsam at that time became more westernized in style, decoration and cutting technologies. For example, it used ironing and pressing setting technology, and breast dart and waist dart to highlight the curve of body. In structure it used traditional kimono sleeves or western set-in sleeves. The western set-in sleeve could make women's shoulder smooth and crisp. Western shoulder pad also was used in cheongsam, called as "shoulder of beauty". Chinese and Western local designs gave cheongsam contour a great breakthrough. On the other hand, Chinese traditional buttons of cheongsam were replaced by western zipper or snap fasteners, which changed the overall style of cheongsam and made it simpler and follow the traces of the times. 


\section{THE ENLIGHTENMENT OF CHEONGSAM STYLE IN THE REPUBLICAN PERIOD ON MODERN FASHION DESIGN}

In the early days of new China, a series of political movements, such as "four clean-ups" and "the Cultural Revolution", have made women clothes masculine. The exquisite and graceful cheongsam was not inherited nor carried forward by our people. It also wasn't influenced by the Western clothing culture for further development and extension. In the 1980s, we has carried out the strategy of the reform and opening up. Our politics, economy and information industry developed rapidly. The return of aesthetic taste makes cheongsam once again return to the stage of clothing, and gradually it get the attention and appreciation of people.

Cheongsam integrates almost all characteristics of Chinese traditional clothing. It is harmonious, smooth, with a unique charm. It leaves people a sense of beauty. We can also see design products of many Western designers using Chinese fashion elements in the international fashion stage which takes the western dress culture as the mainstream. In 1999, Paris designers of haute couture brand Dior use the popular cheongsam style in the period from 1930s to 1940s, and took Shanghai Concession as background to interpret the oriental charm of cheongsam with the Western perspective. The slim cheongsams showed by Western models flowed to upper surface of feet with back exposed and had fishtail trailing, with obvious characteristics of western dress style. Its high collar, Chinese traditional buttons and openings of skirt hemline, delicate roll-off and exquisite embroideries were the shadow of cheongsam. "Cheongsam Fashion" designed by the famous French Designer Yves Saint Laurent has stand collar, Chinese traditional buttons, side opening and other cheongsam elements. The black silk close-fitting dress and puff sleeves show the romance and sexy character of the Western. The skirt hemline reaches to knee, and has the side opening design of cheongsam, which facilitate activity and show the beautiful curve of women's calf. These famous senior fashion brand design makes Chinese people restore the awareness of the national dress culture and re-understand the charm of cheongsam.

At the Red Carpet of the Sixty-third Cannes Film Festival, Film Star Fan Bingbing was wearing a "Golden Dragon Robe", attracting the attention of world's major media. This dress was design by Designer Piao Kewen. It has broad shoulder pads, and is embodied with dragon pattern. It is a cheongsam with fashion characteristics. It not only reserves the delicate and graceful temperament of Oriental women, but also highlights the personality and nobility of dresser. In addition, many films have showed the beauty of cheongsam, such as In the Mood for Love, Love in a Fallen City and Center Stage. They promote the popularity of cheongsam in modern society. With modern aesthetics and fashion elements, cheongsam is favored by more and more fashionable women.

Along with the trend of international assimilation, the Eastern and Western clothing cultures collides and mixes to an extreme. They mutually take in and integrate, making cheongsam style complex, rich and diverse. It reflects the clothing cultures of different countries and peoples are developed and used in different periods and the international circulation is greatly influencing on the Chinese and Western clothing aesthetics.

\section{CONCLUSION}

The fashion trend of cheongsam is influenced by the cultural taste, consciousness and life style of the people who are in a certain period of history, of certain quantity and range. Cheongsam has been a favorite of women, because it has evolved into a national dress of unique style, full of flavor of the times, and integrating the advantages of Chinese and Western clothing. In the era of internationalization of fashion, it is difficult to reproduce the monopoly situation of cheongsam in the heyday. But it is no doubt that its distinctive national characteristics make it constantly sublimate in different times.

In the 21st Century, the Eastern and Western cultures exchange and integrate. Modern concepts propel cheongsam to integrate the process of globalization. It should not be a simple retro to combine the cheongsam styling and modern fashion design. We can take traditional culture as a source of inspiration to extract cheongsam design elements and complementarily use modern meticulous clothing structure and mature clothing cutting technology to enrich design techniques and improve design level. On the basis of tradition, we can add cheongsam with sense of times and reason, and complete the modern inheritance of traditional clothing culture. At the same time, we can take contemporary reality and industry as the basis for development, and promote the dual development of culture and economy.

\section{REFERENCES}

[1] Guo Fei. Looking at the Trend of Chinese Traditional Costume Culture from the Perspective of Changes of Cheongsam. Journal of Beijing Union University. Nov. 20, 2001.

[2] Chen Rongfu \& Chen Yuru. Research on Changes of Cheongsam Style and Structural Design. Journal of Zhejiang Sci-Tech University. Mar. 10, 2007.

[3] Sheng Yu. Discussion on Historical Evolution and Social Value of Cheongsam. Journal of Ningbo University (HUMANITIES SCIENCE EDITION). Sept. 30, 2003. 